\section{Meta-analysis Study of Achievement Motivation and Academic Achievement}

\author{
Atanasius Emillio Gary Waluyohadi \\ Magister Psikologi Sains \\ Universitas Surabaya \\ E-mail: atanasius.gary@guru.pppkpetra.or.id.
}

\section{Journal PSIKODIMENSIA}

Volume 18, No. 2,

Juni - Desember 2019

ISSN cetak : 1411-6073

ISSN online : 2579-6321

DOI :10.24167/psidim.v18i2.2023

\begin{abstract}
Academic achievement becomes something important for students. Academic achievement has a relationship with achievement motivation. Based on the results of a review of the literature, there is an inconsistency in the results of research on the relationship of academic achievement with achievement motivation. Therefore, the author conducted a meta-analyst with a significant effect size correlation with academic achievement $(r=0.334508)$ and significant with CI (0.170255; 0.480675). The results of the I2 statistical test showed a high inconsistency with a value of $98.7 \%$. There is also high heterogeneity in the results of this meta-analysis with the value of Cohcran $Q$ showing 1,029.604289. The relationship between the two variables also shows the bias by looking at the results of the egger, which is 9.311441. The results of statistical tests show that achievement motivation and academic achievement have a fairly high effect size correlation. The heterogeneity in this meta-analysis is high and there is publication bias.
\end{abstract}

Keyword : academic achievement, achievement motivation, meta-analyst.

\section{PENDAHULUAN}

Dalam UUD 1945 pasal 31 ayat 1 mengemukakan bahwa setiap warga negara berhak mendapat pendidikan. Hak mengenyam pendidikan yang layak memang diperuntukkan bagi masyarakat Indonesia. Pendidikan di Indonesia memiliki dua bagian, yaitu pendidikan dasar dan pendidikan menengah. Pendidikan dasar berupa SD/MI dan SMP/MTs dan dilanjutkan pada pendidikan menengah yang berupa SMA/MA dan SMK. Pendidikan di Indonesia diwujudkan dalam sebuah sekolah. Tujuan dari sebuah sekolah adalah para siswa dapat menambah ilmu pengetahuan, pengembangan karakter pribadi yang siap terjun di masyarakat, mengarahkan para siswa menuju cita - cita yang diharapkan. Hal ini tertuang pada
Undang-Undang No. 20 Tahun 2003 Pasal 3 mengenai fungsi pendidikan nasional yaitu mengembangkan kemampuan dan membentuk watak serta peradaban bangsa yang bermartabat dalam rangka mencerdaskan kehidupan bangsa.

Penyelenggaraan pendidikan di Indonesia saat ini berdasarkan pada kurikulum 2013. Kurikulum 2013 menerapkan standar kompetensi lulusan yang terdiri dari 3 dimensi, yaitu sikap, pengetahuan dan keterampilan. Setiap jenjang mulai dari SD sampai SMA memiliki kualifikasi kemampuan yang berbeda-beda sesuai Peraturan Menteri Pendidikan dan Kebudayaan No. 54 Tahun 2018 khususnya pada jenjang SMA.

Pandangan mengenai sebuah sekolah pada jenjang SMA memperlihatkan remaja 
suka mengeluh tentang sekolah seperti pelajaran yang berat, larangan-larangan di sekolah, pekerjaan rumah yang terlalu banyak. Mereka bersikap kritis terhadap guru - guru dan cara guru mengajar. Para siswa merasa kelelahan saat menghadapi masa sekolah karena setiap Senin - Jumat diharuskan belajar dengan tujuh belas mata pelajaran dan kegiatan ekstrakurikuler. Kondisi yang mengharuskan para siswa memiliki prestasi akademik maupun non akademik.

Prestasi akademik menjadi sebuah kewajiban yang harus diraih oleh para siswa selama masih dalam proses belajar di sebuah institusi pendidikan.Prestasi akademik adalah sebuah penilaian yang menunjukkan kinerja para siswa untuk memenuhi standar. Seiring dengan standar prestasi akademik, skor rata - rata menjadi sebuah indikator yang sering dipakai untuk melihat prestasi akademik siswa. (Dinger, Felix C., Oliver Dickhauser, Birgit Spinath, Ricarda Steinmayr. 2013).

Prestasi akademik sebagai tolok ukur para siswa untuk dapat naik ke jenjang kelas yang lebih tinggi daripada sebelumnya. Sebuah prestasi akademik menjadi sebuah pertanda bahwa sukses atau tidaknya dalam siswa tersebut dalam menempuh studi selama satu tahun ajaran. Prestasi akademik biasanya diukur dalam bentuk angka dan memberikan standar ketuntasan minimal belajar. Apabila siswa tidak memenuhi kriteria yang telah ditentukan oleh dewan sekolah, maka kemungkinan tidak naik kelas. Hal ini menjadi penting untuk diperjuangkan dalam pendidikan bagi siswa.

Prestasi akademik dapat melihat kualitas dari siswa yang akan menempuh studi lanjut di Perguruan Tinggi. Mereka akan melihat hasil belajar setiap semester untuk menentukan diterima atau tidak dalam Perguruan Tinggi. Seringkali, para siswa tidak mementingkan hal tersebut dan terkesan santai dalam belajar. Mereka belajar jika hanya ada ulangan atau tugas, sehingga tidak menjadi sebuah rutinitas dalam kehidupan sehari-hari.

Dalam mencapai sebuah prestasi yang baik, maka para siswa membutuhkan sebuah motivasi untuk belajar. Meningkatkan motivasi belajar siswa memang menjadi sebuah tantangan bagi para guru yang berada di sekolah. Motivasi akademik yang dimiliki oleh para siswa dalam secara internal maupun eksternal. Motivasi internal mengarah kepada diri sendiri dan motivasi eksternal berasal dari lingkungan sekitar seperti guru, orang tua, teman, dan lain-lain.

Sepuluh tahun terakhir, ada beberapa hasil penelitian terkait dengan hal tersebut. Penelitian yang dikemukakan Bakar, Tarmizi, Mahyuddin, Elias, Luan, Ayub (2010) menunjukkan kesimpulan yang berbeda untuk achievement motivation dan academic achievement. Penelitian dilakukan kepada 1484 mahasiswa dari universitas negeri di Malaysia. Hasil penelitian menunjukkan adanya korelasi negatif $(\mathrm{r}=$ $0,038, p>0,05)$ dan signifikan antara motivasi berprestasi dengan prestasi akademik.

Emmanuel, Adom, Josephine, dan Solomon (2014) memberikan hasil penelitian yang berbeda dengan penelitan Bakar, et.al. Hasil penelitian yang dilakukan kepada 120 siswa SMA di keempat sekolah wilayah barat Ghana. Penelitian menunjukkan bahwa tidak signifikan ( $\mathrm{r}=$ $0.03, \mathrm{p}>0,01)$ antara achievement motivation dengan academic achievement.

Joseph, R., \& Viswanathappa. (2017) mengungkapkan hasil penelitian bahwa achievement motivation memiliki hubungan signifikan positif $(\mathrm{r}=0.651, \mathrm{p}<0.01)$ dengan academic achievement. Penelitian ini dilakukan kepada 270 siswa yang menempuh studi di kota Kigali, Rwanda.

Berdasarkan hasil tinjauan literatur menunjukan adanya inkonsistensi hasil penelitian tentang hubungan prestasi 
akademik dengan achievement motivation. Maka, untuk meningkatkan keakuratan dan keandalan hasil meta analisis terkait dua variabel ini, penulis melakukan meta analisis hubungan antara prestasi akademik dengan achievement motivation. Meta analisis ini bertujuan untuk mencari tahu seberapa besar effect size correlation prestasi akademik dengan achievement motivation.

\section{METODE}

Dalam melakukan penelitian meta analisis terdapat langkah - langkahnya menurut DeCoster (2009) diantaranya, menentukan dan mempelajari topik penelitian yang akan dirangkum, mencari dan mengumpulkan sejumlah penelitian dengan topik yang telah ditentukan dan menyeleksinya, melakukan perhitungan effect size dengan metode dalam meta analisis, mengidentifikasi ada tidaknya heterogenitas effect size, dan menarik kesimpulan dan menginterpretasi hasil penelitian meta analisis.

Penulis mempelajari dan menentukan topik penelitian meta analisis yaitu achievement motivation dan academic achievement dengan latar belakang masalah yang sudah diuraikan sebelumnya. Langkah berikutnya, penulis melakukan screening literatur dari dua website, yaitu google scholar dan science direct. Pencarian dilakukan dari bulan Oktober 2018 sampai November 2019. Data yang diperoleh memfokuskan berasal dari jurnal internasional penelitian ilmiah yang meneliti hubungan prestasi akademik dengan achievement motivation.

Pencarian literatur menggunakan kata kunci yaitu achievement motivation, academic achievement. Penyaringan dilakukan dengan meninjau judul penelitian terlebih dahulu. Kemudian, apabila judul sesuai dengan topik maka penyaringan dilanjutkan dengan melihat abstrak penelitian. Jika abstrak penelitian sudah memperlihatkan hasil $r$ (korelasi) dan $n$ (jumlah subyek), maka penulis memilih jurnal tersebut. Jika abstrak penelitian belum ditemukan hasil $r$ dan $n$, maka penulis harus membaca isinya terlebih dahulu untuk dilihat hasilnya.

Penulis membatasi tahun penerbitan jurnal, yaitu tahun 2008 - 2019. Dalam website science direct muncul 15.062 jurnal dan penulis masih melihat 400 jurnal. Kemudian, dari 400 jurnal maka ditemukan 33 jurnal yang ada kaitannya dengan dua variabel sampai dengan tanggal 25 November 2019. Tiga puluh tiga jurnal terdapat 5 jurnal penelitian yang ada hasil korelasinya.

Kemudian, penulis mencari di google scholar dengan membatasi tahun penerbitan jurnal, yaitu tahun 2008 - 2019. Kata kunci yang digunakan adalah achievement motivation and academic achievement. Dari 790 jurnal yang dilihat, maka ditemukan yang sesuai dengan variabel dan hasil penelitiannya sebanyak 9 jurnal. Maka, penulis sudah menemukan 14 jurnal yang akan dijadikan bahan meta analisis.

Jurnal penelitian yang sudah terpilih, dipilah menjadi 3 informasi diantaranya nama peneliti dan tahun diadakannya penelitian, jumlah subyek, korelasi penelitian. Ringkasan informasi dapat dilihat dalam tabel 1. Studi ini memperlihatkan effect size correlation antara prestasi akademik dengan achievement motivation. Penulis menggunakan program stats direct untuk menemukan hasil effect size, mengidentifikasi dan menginterpretasi hasil penelitian meta analisis. 
Tabel 1. Data penelitian 14 jurnal untuk meta analisis

\begin{tabular}{lccc}
\hline \multicolumn{1}{c}{ Nama } & Tahun & N & R \\
\hline $\begin{array}{l}\text { Kamariah Abu Bakar, Rohani Ahmad Tarmizi, Rahil Mahyuddin, } \\
\text { Habibah Elias, }\end{array}$ & 2010 & 1484 & 0,038 \\
Wong Su Luan, Ahmad Fauzi Mohd Ayub & & & \\
\hline $\begin{array}{l}\text { Firoozeh Bakhtiarvand, Sana Ahmadian, Kazem Delrooz, Hojjat A. } \\
\text { Farahani }\end{array}$ & 2011 & 200 & $-0,30$ \\
\hline $\begin{array}{l}\text { Kourosh Amrai, Shahrzad Elahi Motlagh, Hamzeh Azizi Zalani \& } \\
\text { Hadi Parhon }\end{array}$ & 2011 & 252 & 0,04 \\
\hline Ali Akbar Sheikhi Fini, Mitra Yousefzadeh & 2011 & 211 & 0,95 \\
\hline Mahdi Moenikiaa, Adel Zahed-Babelanb & 2011 & 33982 & 0,21 \\
\hline P. Imani, S. Subramanian & 2016 & 225 & 0,128 \\
\hline O. U Onete, P. B. Edet, F. U. Udey, Peter Ogbor & 2012 & 750 & 0,63 \\
\hline Rwandema Joseph, G. Viswanathappa & 2017 & 270 & 0,651 \\
\hline $\begin{array}{l}\text { Affum Osei Emmanuel, Eric Asante Adom, Forkuoh Kwarteg } \\
\text { Solomon, Barnie Josephine }\end{array}$ & 2014 & 120 & 0,03 \\
\hline Palak K. Lakhani, Kusum Jain, Payal Kanwar Chandel & 2017 & 120 & $-0,159$ \\
\hline T. D. Sikhwari & 2014 & 193 & 0,215 \\
\hline Sita Chetri & 2014 & 480 & 0,189 \\
\hline Taisha Caldwell and Ezemenari M. Obasi & 2010 & 202 & 0,57 \\
\hline Michelle Ricahrdson and Charles Abraham & 2009 & 570 & 0,43 \\
\hline Sumber : Perhitungan Statdirect) & & & \\
\hline
\end{tabular}

(Sumber : Perhitungan Statdirect)

\section{HASIL}

Penelitian yang dilakukan dengan 14 jurnal menunjukkan effect size correlation dengan total sampel sebanyak 39.059 partisipan. Berikut ini tabel yang merangkum hasil studi literatur tentang prestasi akademik dengan achievement motivation dari 14 jurnal penelitian.

\section{Tabel 2. Hasil Statistik Meta Analisa Prestasi Akademik dan Achievement Motivation.}

\begin{tabular}{|c|c|}
\hline $\mathbf{Q}$ & Egger \\
\hline $1.029,6043$ & $9,311^{* * *} *$ \\
\hline
\end{tabular}

Keterangan : $\mathrm{r}=$ korelasi, $\mathrm{Q}=$ Cochran, $\mathrm{I}^{2}=$ Inconsistency, $* * *(\mathrm{p}<0,0001)$

(Sumber : Perhitungan Statdirect)

Effect size correlation, Konsistensi Data, dan Heterogenitas

Achievement motivation memiliki effect size correlation yang cukup besar dengan prestasi akademik $(\mathrm{r}=0,334508)$ dan signifikan dengan $\mathrm{CI}(0,170255$ to 0,480675). Effect size correlation dilihat dari nilai pooled correlation Hedges-Olkin random effects. Korelasi dianggap rendah apabila nilainya $<0,1$, dikategorikan sedang apabila nilai < 0,3 dan kategori besar apabila nilainya $\geq 0,5$.

\section{Tabel 3. Hasil uji Inkonsistensi}

Hasil uji statistik $\mathrm{I}^{2}$ menunjukkan inkonsistensi yang tinggi untuk prestasi akademik dengan achievement motivation dengan nilai $98,7 \%$. Inkonsistensi penelitian

\begin{tabular}{|c|c|c|}
\hline $\mathbf{R}$ & $\mathbf{9 5 \%} \mathbf{C I}$ & $\mathbf{I}^{\mathbf{2}}(\mathbf{\%})$ \\
\hline $0,3345^{* * *}$ & $\begin{array}{c}0,170255 \text { to } \\
0,480675\end{array}$ & $98,7 \%$ \\
\hline
\end{tabular}

disajikan dalam nilai $\mathrm{I}^{2}$ dalam bentuk nilai persen. Semakin besar persentase maka semakin besar pula inkonsistensi penelitian. Penelitian mengenai achievement motivation dan academic achievement mengalami perubahan dan tidak selalu sama dalam hasil pengukurannya, sehingga memengaruhi heterogenitas. Dalam meta analisis ini 
terdapat heterogenitas yang tinggi dengan nilai Cohcran $Q$ menunjukkan 1.029,604289. Hubungan kedua variabel menunjukkan pula adanya bias dengan melihat hasil egger yaitu 9,311441. Nilai Egger untuk melihat kecenderungan bias.
Jika semakin bias, berarti hubungan kedua variabel semakin tidak baik. Nilai taraf signifikan apabila $\mathrm{p}<0,05$.

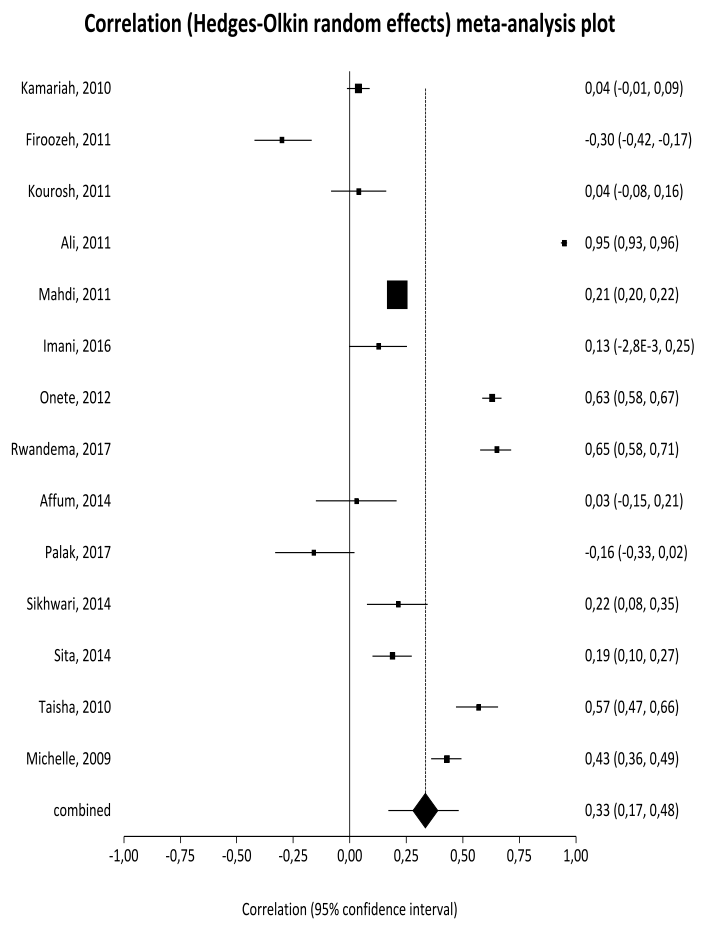

Gambar 1

Forest plot untuk meta analisis achievement motivation dan academic achievement

(Sumber : Statdirect)

\section{DISKUSI}

Prestasi akademik menjadi salah satu tolok ukur keberhasilan dalam dunia pendidikan. Prestasi akademik dinilai penting bagi para siswa karena menjadi salah satu persyaratan dalam melanjutkan pendidikan ke jenjang berikutnya. Dalam mencapai prestasi akademik, ada beberapa faktor yang memengaruhi dan salah satunya adalah achievement motivation.
Studi meta analisis akan menyajikan beberapa literatur dari hasil penelitian mengenai achievement motivation dan academic achievement. Pada studi meta analisis menunjukkan bahwa achievement motivation memiliki dampak yang cukup baik untuk meningkatkan prestasi akademik. Akan tetapi, penulis memperhatikan hasil inkonsistensi penelitian menunjukkan nilai yang tinggi. Hal ini dapat terjadi karena setiap hasil penelitian jurnal yang ditemukan 
memiliki data yang bervariasi yang menunjukkan adanya korelasi negatif dan korelasi yang positif, seperti yang dapat dilihat pada gambar 1 dalam forest plot.

Hasil korelasi yang bervariasi akan menunjukkan hasil yang heterogenitas yang tinggi Dalam ulasan penelitian yang digunakan sebagai data meta analisis ini bahwa para peneliti tidak hanya membahas mengenai achievement motivation, namun ada variabel lain yang memengaruhi academic achievement diantaranya inteligensi, sikap, konsep diri, perbedaan dalam belajar, dan locus of control.

Faktor lainnya yang memengaruhi biasnya suatu meta analisis adalah achievement motivation memiliki 2 aspek menurut $\mathrm{Yu}$ dan Yang (dalam Liem, dkk. 2012), yaitu individual-oriented dan socialoriented. Individual-oriented memiliki kecenderungan yaitu adanya tekad untuk berprestasi sesuai dengan standar yang ditentukan diri sendiri. Berbeda dengan social-oriented yang kecenderungan memiliki tekad untuk berprestasi karena sesuai dengan standar. Kedua aspek ini bisa memengaruhi hasil meta analisis yang bias.

Proses mencapai sebuah prestasi akademik ternyata tidak hanya mengarah pada motivasi akademik saja melainkan ada faktor lain yang memengaruhi, maka akan berdampak pada sebuah studi meta analisis yang menunjukkan adanya sebuah bias. Menurut DeCoster (2009) memang salah satu kelemahan dalam meta analisis yaitu publication bias. Publication bias yang dimaksudkan adalah dalam meta analisis ini menggunakan data yang terdapat penelitian yang telah terpublikasi sehingga dianggap penelitian tidak representatif karena hasil hasil pengamatan yang signifikan lebih cenderung dipublikasikan daripada yang tidak signifikan.

\section{SIMPULAN}

Hasil uji statistika meta analisis menunjukkan bahwa achievement motivation dan prestasi akademik memiliki effect size correlation yang cukup tinggi, sehingga dapat dikatakan achievement motivation memiliki sumbangan relatif cukup baik dalam meningkatkan prestasi akademik. Heterogenitas dalam meta analisis ini adalah tinggi dan adanya bias publikasi. Hal ini menunjukkan ada faktor lain yang memengaruhi prestasi akademik diantaranya inteligensi, sikap, konsep diri, perbedaan dalam belajar, dan locus of control.

Penelitian studi meta analisis ini memiliki kelemahan yaitu pemilihan jurnal penelitian yang disertai variabel lain dan mengalami kesulitan apabila jurnal tersebut hanya mencakup dua variabel saja, jumlah subyek dan karakteristik subyek dalam jurnal penelitian yang dipakai dalam meta analisis masih perlu ditambahkan. Saran dalam studi meta analisis selanjutnya adalah penulis dapat menambahkan jumlah penemuan jurnal penelitian baik nasional maupun internasional mengenai kedua variabel tersebut dengan mengkaji variabel lain sebagai moderator atau mediator dalam prestasi akademik. 


\section{DAFTAR PUSTAKA}

Amrai, K., Motlagh, S. E., Zalani, H. A., \& Parhon, H. (2011). The relationship between academic motivation and academic achievement students. Procedia Social and Behavioral Sciences 15 , 399-402. Retrieved from https://doi.org/10.1016/j.sbspro.2011. 03.111

Bakar, K. A., Tarmizi, R. A., Mahyuddin, R., Elias, H., Luan, W. S., \& Ayub, A. F. (2010). Relationship between univesity students achievement motivation, attitude and academic performance in Malaysia . Procedia Social and Behavioral Science , 49064910. Retrieved from https://doi.org/10.1016/j.sbspro.2010. 03.793

Bakhtiarvand, F., Ahmadian, S., Delrooz, K., \& Farahani, H. A. (2011). The Moderating Effect of Achievement Motivation on Relationship of Learning Approaches and Academic Achievement. Procedia Social and Behavioral Sciences 28 , 486-488. Retrieved from https://doi.org/10.1016/j.sbspro.2011. 11.093

Caldwell, T., \& Obasi, E. M. (2010). Academic Performance in African American Undergraduates : Effects of Cultural Mistrust. Educational Value, and Achievement Motivation. Journal of Career Development , 348-369. Retrieved from https://doi.org/10.1177/089484530934 9357
Chetri, S. (2014). Achievement Motivation of Adolescents and Its Relationship with Academic Achievement. International Journal of Humanities and Social Science Invention , 8-15. Retrieved from http://ijhssi.org/papers/v3(6)/Version1/C036108015.pdf

DeCoster, J. (2009). Meta-Analysis Notes. Retrieved November 27, 2019 from http://www.stathelp.com/notes.html

Dinger, F. C., Dickhauser, O., Spinath, B., \& Steinmayr, R. (2013). Antecedents and consequences of students achievement goals : A mediation analysis. Learning and Individual Differences , 90-101. Retrieved from https://doi.org/10.1016/j.lindif.2013.0 9.005

Emmanuel, A.-O., Adom, E. A., Josephine, B., \& Solomon, F. K. (2014). Achievement motivation, academic self-concept and academic achievement among high school students. European Journal of Reserach and Reflection in Educational Sciences. Retrieved from https://www.researchgate.net/publicati on/286496437_ACHIEVEMENT_M OTIVATION_ACADEMIC_SELFCONCEPT_AND_ACADEMIC_AC HIEVEMENT_AMONG_HIGH_SCH OOL_STUDENTS

Fini, A. A., \& Yousefzadeh, M. (2011). Survey on relationship of achievement motivation, locus of control, and academic achievement in high school students of Bandar Abbas. Procedia 
Social and Behavioral Sciences 30 , 866-870. Retrieved from https://doi.org/10.1016/j.sbspro.2011. 10.168

Imani, P., \& Subramanlan, S. (2017). Achievement motivation and academic achievement of higher secondary students - locality wise analysis. Indian Journal of Research , 504-505. Retrieved from https://wwjournals.com/index.php/pijr /article/view/10628

Joseph, R., \& Viswanathappa, G. (2017). Relationship between achievement motivation and academic achievement of secondary school student of Kagali City, Rwanda. International Journal of Scientific Research , 746-747. Retrieved from https://wwjournals.com/index.php/ijsr/ article/view/15777

Lakhani, P. K., Jain, K., \& Chandel, P. K. (2017). School Adjustment, Motivation and Academic Achievement among students. International Journal of Research in Social Sciences , 333-348. Retrieved from

https://www.researchgate.net/publicati on/321741311_School_Adjustment_ Motivation_and_Academic_Achievem ent_among_Students

Liem, Gregory Arief, Andrew J. Martin, Amy L. Porter. Susan Colmar. 2012. Sociocultural antecedents of academic motivation and achievement: Role of values and achievement motives in achievement goals and academic performance. Asian Journal of Social Psychology 15, 1 - 13. Retrieved from https://doi.org/ 10.1111/j.1467-

839X.2011.01351.x

Moenikia, M., \& Zahed-Babelan, A. (2010). A study of simple and multiple relations between mathematics attitude, academic motivation, and intelligence quotient with mathematics achievement. Procedia Social and Behavioral Sciences 2 , 1537-1542. Retrieved from https://doi.org/10.1016/j.sbspro.2010. 03.231

Onete, O. U., Edet, P. B., Udey, F. U., \& Ogbor, B. P. (2012). Academic Performance : A Function of Achievement Motivation Among Education Students of Cross River University of Technology, Calabar. Review of Higher Education in Africa , 63-83. Retrieved from https://journal.lib.uoguelph.ca/index.p $\mathrm{hp} /$ rhea/article/view/2185

Richardson, M., \& Abraham, C. (2009). Conscientiousness and Achievement Motivation Predict Performance. European Journal of Personality , 589605. Retrieved from https://doi.org/10.1002/per.732

Sikhwari, T. D. (2014). A Study of the Relationship between Motivation, Self-concept and Academic Achievement of Students at a University in Limpopo Province, South Africa. International Journal Educational Science , 19-25. Retrieved from https://doi.org/10.1080/09751122.201 4.11890113 